\title{
Experimental Study on Thermal Lord Characteristics of R245fa in Circular Plate
}

\author{
Kibong Kim ${ }^{1,3}$, Ki-Chang Chang ${ }^{1}$, Hosang $\mathrm{Ra}^{1}$, Yongchan Kim ${ }^{2}$ \\ ${ }^{1}$ Thermal Energy Systems Laboratory, Korea Institute of Energy Research \\ 152 Gajeong-ro, Yuseong-gu, Daejeon, 34129, Korea \\ kimkibong@kier.re.kr ; kcchang@kier.re.kr ; hsra@kier.re.kr \\ ${ }^{2}$ Department of Mechanical Engineering, Korea University \\ 145 Anam-ro, Seongbuk-gu, Seoul, 02841, Korea \\ yongckim@korea.ac.kr \\ ${ }^{3}$ Department of Mechanical Engineering Graduate School, Korea University \\ 145 Anam-ro, Seongbuk-gu, Seoul, 02841, Korea
}

\section{Extended Abstract}

This paper is an experimental study on the thermal load characteristics of the working fluid R245fa in a Plate Shell Heat Exchanger (PSHE) using a circular plate as the condenser of a Steam Generation Heat Pump (SGHP)[1].

We experimented with the condensation heat transfer, temperature gradient in the circular plate [2, 3]. In PSHE as a condenser of SGHP, hot side of the refrigerant flows to the downward and transfers the heat, on the other side, cold side the water flows to the upward and receives the heat to be pressurized water. And then the pressurized water is separated from condensate water and steam in flash tank.

Experimental conditions were investigated according to mass flux, heat flux, saturation temperature and mean vapor quality. As a result of this study, the condensation heat transfer coefficient is strongly dependent on the mass flux and mean vapor quality. Because the flow regime is convective boiling. Also, the temperature gradient is dependent on the Reynolds number and temperature. It is largely changed the temperature gradient at the edge of the circular plate where the flow rate was slow.

In the future, we will conduct the experiments on the pressure drop, visualization and other refrigerant instead of R245fa in PSHE.

\section{References}

[1] K. C. Chang, S. R. Park, K. B. Kim, "Thermal load characteristics of high-temperature condenser for steam heat pump," in Proceedings of the SAREK Winter Annual Conference, Korea, pp. 375-376.

[2] J. H. Park, Y. S. Kim, M. G. Seo, "Experimental Study on R134A Condensation Heat Transfer Characteristics in Plate and Shell Heat Exchangers," in Proceedings of the International Refrigeration and Air Conditioning Conference, Purdue University, USA, 2002.

[3] L. A. Raffaele, J. R. Thome, "High Resolution infrared measurements of Single-Phase Flow of R245fa and R236fa within a Compact Plate Heat Exchanger, Part 1: Experimental Setup and Pressure Drop Results," Applied Thermal Engineering, vol. 101, pp. 545-554, 2016. 